\title{
Electrochemical Characterization, Detoxification and Anticancer Activity of Didodecyldimethylammonium Bromide
}

\author{
Afzal Shah ${ }^{1}$, Erum Nosheen ${ }^{1}$, Rumana Qureshi ${ }^{1}$, Muhammad Masoom Yasinzai ${ }^{1}$, \\ Suzanne K. Lunsford ${ }^{2}$, Dionysios D. Dionysiou ${ }^{3}$, Zia ur Rehman ${ }^{1}$, Muhammad Siddiq ${ }^{1}$, \\ Amin Badshah ${ }^{1}$, Saqib Ali ${ }^{{ }^{*}}$ \\ ${ }^{1}$ Department of Chemistry, Quaid-i-Azam University, Islamabad, Pakistan \\ ${ }^{2}$ Department of Chemistry, Wright State University, Dayton, USA \\ ${ }^{3}$ School of Energy, Environmental, Biological, and Medical Engineering (SEEBME), \\ 705 Engineering Research Center, University of Cincinnati, Cincinnati, USA \\ E-mail:"drsa54@yahoo.com \\ Received October 20, 2011; revised November 27, 2011; accepted December 6, 2011
}

\begin{abstract}
Quaternaryammonium compounds (QACs) are cationic surfactants with broad range applications. They enter into aquatic environment through the discharge of sewage effluents and adversely affect the ecosystem due to toxicity. Modern electrochemical methods have been used for characterization and detoxification of an extensively used QAC, didodecyldimethylammonium bromide (DDAB) in a wide $\mathrm{pH}$ range. The diffusion coefficient of DAAB was determined by Randles-Sevcik equation. In acidic conditions the electrochemical reduction of $\mathrm{DAAB}$ occurred by two electrons and two protons process. However, in neutral medium the overall reduction of DAAB followed electronation-protonation mechanism involving $3 \mathrm{e}^{-}$and $3 \mathrm{H}^{+}$. Although DDAB is toxic yet it is bestowed with cancer preventing ability. Hence, for getting insights into the understanding of DAAB anticancer effect, its DNA binding parameters has been evaluated.
\end{abstract}

Keywords: Didodecyldimethylammonium Bromide, Detoxification, Anticancer Effect, DNA Binding Parameters

\section{Introduction}

Surfactants are widely used as household and industrial cleaning agents. They are classified as: cationic, anionic, non-ionic and zwitterionic. Quaternary ammonium compounds (QAC) are the most extensively studied surface active agents. They are mainly used as slimicides in swimming pools, antistatic agents in hair conditioners and wetting agents in nasal sprays $[1,2]$. Moreover, they also find use in preservatives, shampoos and dish washing materials [3].

The used surfactants find their way to various environmental segments and thus pose serious health hazards. They have the ability to adsorb strongly onto negatively charged suspended particulates and sludge. Intensive investigations have been carried out on their behavior, fate and biological effects [4,5]. Long exposure to QACs can cause sensitization, haemolysis and toxic effects by all routes of exposure including inhalation, ingestion, dermal application and irrigation of body cavities [6]. Their toxicity in the $\mathrm{mg} \cdot \mathrm{l}^{-1}$ range with a fatal dose of $1-3 \mathrm{~g}$ has been reported [7]. The concentrated solutions of QACs result in allergic reactions, hypersalivation, vomiting, haematemesis and diarrhoea [8]. In severe cases they may cause respiratory paralysis, convulsions, coma and cardiorespiratory arrest [9]. A part of the current article is devoted to voltammetric characterization and detoxification of a quaternary ammonium compound, didodecyldimethylammonium bromide (DDAB) by modern electrochemical techniques.

DDAB (Scheme 1) is toxic as well as cancer preventing agent [10]. Toxicity is a major nuisance of anticancer drugs. Most of the clinically used anticancer drugs have a narrow therapeutic index, with a small difference in their dose for antitumor effect and toxicity. Therefore, the doses recommended for such compounds are determined 


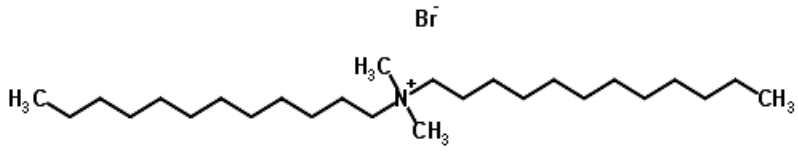

Scheme 1. Chemical structure of DAAB.

according to their toxicity endpoints. Considerable research work has been carried out on the cancer prevention ability of DAAB but the mechanism of action has not been explored. The present work is an effort to establish a critical role of DDAB in exercising its anticancer effect.

The main cause of several diseases such as diabetes, hemophilia and cancer is related to the alteration in the replication machinery of DNA. Therefore, drug interacttions with DNA which can affect the replication processes, are potential treatments for such ailments [11-13]. Normally, cancers are difficult to be diagnosed at a stage of small hidden tumors, so the surgical eradication can not be practiced. At such an early stage, chemotherapy is the only weapon to combat with cancer. The research focused on the action mechanism of anticancer drugs is expected to accelerate the discovery of effective chemotherapeutic agents.

A variety of techniques has been employed [14-18] for the study of toxicity alleviation and drug-DNA interaction with relative advantages and disadvantages. However, most of these suffer from high cost, low sensitivity and procedural complication. Electrochemical techniques were used for the characterization, detoxification and DNA binding studies of DAAB due to their cost effecttivity, high sensitivity and ease of operation.

\section{Experimental}

\subsection{Materials and Reagents}

DDAB (98\% purity) was purchased from Fluka and used without further purification. Its $5.0 \mathrm{mM}$ stock solution was prepared and stored at $4{ }^{\circ} \mathrm{C}$. The working solutions were prepared in 1:1 mixed solvent of ethanol and buffer. All supporting electrolyte solutions (Table 1) were prepared using analytical grade reagents. Calf thymus DNA was purchased from Sigma and used as received. $2.0 \mathrm{mM}$ stock solution of DNA was prepared and its concentration was determined by UV absorbance at $260 \mathrm{~nm}$ using a molar absorptivity $(\varepsilon)$ of $6600 \mathrm{M}^{-1} \mathrm{~cm}^{-1}[19,20]$. As the absorbance ratio of pure DNA at 260 and $280 \mathrm{~nm}$ $\left(A_{260} / A_{280}\right)$ should not be less than 1.8 , so a ratio of 1.85 indicated protein free DNA [21]. Doubly distilled water was used throughout.
Table 1. List of $0.1 \mathrm{M}$ supporting electrolytes.

\begin{tabular}{cccc}
\hline $\mathrm{pH}$ & Composition & $\mathrm{pH}$ & Composition \\
\hline 1.0 & $\mathrm{HCl}+\mathrm{KCl}$ & 7.0 & $\mathrm{NaH}_{2} \mathrm{PO}_{4}+\mathrm{Na}_{2} \mathrm{HPO}_{4}$ \\
2.0 & $\mathrm{HCl}+\mathrm{KCl}$ & 8.0 & $\mathrm{NaH}_{2} \mathrm{PO}_{4}+\mathrm{Na}_{2} \mathrm{HPO}_{4}$ \\
3.0 & $\mathrm{HAcO}+\mathrm{NaAcO}$ & 9.0 & $\mathrm{NaHCO}_{3}+\mathrm{NaOH}$ \\
4.0 & $\mathrm{HAcO}+\mathrm{NaAcO}$ & 10.0 & $\mathrm{NH}_{3}+\mathrm{NH}_{4} \mathrm{Cl}$ \\
5.0 & $\mathrm{HAcO}+\mathrm{NaAcO}$ & 12.0 & $\mathrm{NaOH}+\mathrm{KCl}$ \\
6.0 & $\mathrm{HAcO}+\mathrm{NaAcO}$ & 13.0 & $\mathrm{NaOH}+\mathrm{KCl}$ \\
\hline
\end{tabular}

\subsection{Equipments and Measurements}

Voltammetric experiments were performed using $\mu$ Autolab running with GPES 4.9 software, Eco-Chemie, The Netherlands. A glassy carbon (GC) $\left(\mathrm{A}=0.07 \mathrm{~cm}^{2}\right)$ was used as working electrode, a Pt wire served as counter electrode and a saturated calomel electrode (SCE) was employed as the reference. The differential pulse voltammetry (DPV) and square wave voltammetry (SWV) were carried out at a scan rate of 10 and $100 \mathrm{mV} \cdot \mathrm{s}^{-1}$. Cyclic voltammetry $(\mathrm{CV})$ was performed at different scan rates. Before each experiment the surface of GCE was polished with alumina powder followed by thorough rinsing with distilled water. All the voltammetric experiments were conducted in a high purity nitrogen $(99.995 \%)$ atmosphere at room temperature $\left(25^{\circ} \mathrm{C} \pm 1^{\circ} \mathrm{C}\right)$.

Viscosity and density measurements were made on an Anton Paar Stabinger Viscometer SVM 3000. The dynamic laser light scattering experiment was carried out by a commercial LLS spectrometer BI-200SM motor-driven goniometer equipped with BI-9000AT digital autocorrelator and a cylindrical $22 \mathrm{~mW}$ uniphase He-Ne laser (wavelength $=637 \mathrm{~nm}$ ) and BI-ISTW software.

\section{Results and Discussion}

\subsection{Cyclic Voltammetry}

Cyclic voltammetric (CV) behavior of DDAB has been examined in $\mathrm{pH}$ range 1 - 13. In acidic and neutral media, DDAB was found to give two cathodic peaks corresponding to two step reduction while a single anodic peak related to oxidation was registered in alkaline media. Figures 1(a)-(c) show typical cyclic voltammograms of 1.0 $\mathrm{mM}$ DDAB in different $\mathrm{pH}$ media. In strongly acidic conditions ( $\mathrm{pH} 2.0$ ) two close reduction peaks were recorded in the forward scan with no corresponding oxidation peaks in the reverse scan. In a medium buffered at $\mathrm{pH}$ 7.0, a broad reduction peak $\left(1_{\mathrm{c}}\right)$ was observed which may be due to the overlapping two close cathodic peaks appeared in harsh acidic environment. The $2^{\text {nd }}$ cathodic peak appeared at high negative value. The $\mathrm{CV}$ of $\mathrm{DAAB}$ at $\mathrm{pH} 13.0$ showed only oxidation. The variation in $\mathrm{CV}$ response indicates that the redox mechanism of DDAB is $\mathrm{pH}$ dependent. 


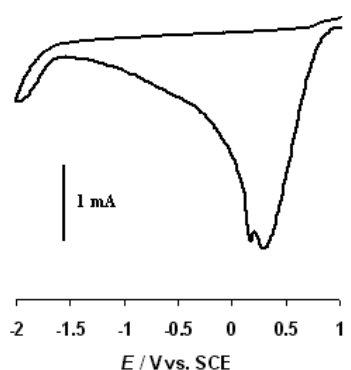

(a)

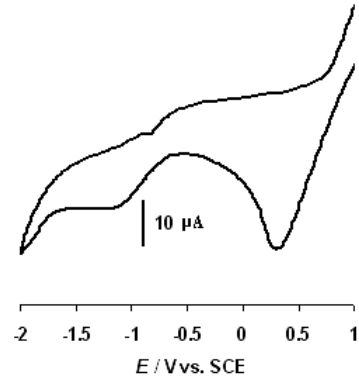

(b)

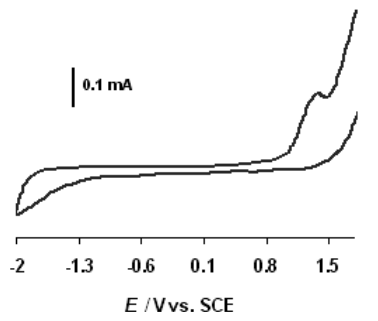

(c)

Figure 1. CVs 1.0 mM DDAB in pH (a) 2.0, (b) 7.0 and (c) 13.0 at $\mathrm{v}=100 \mathrm{mV} \cdot \mathrm{s}^{-1}$.

The dependence of peak current $I_{p}$, on the scan rate, $v$, is an important diagnostic criterion for establishing the type of mechanism by cyclic voltammetry. Therefore, CVs of DDAB were recorded at different scan rates (100 $500 \mathrm{mV} \cdot \mathrm{s}^{-1}$ ). The shift in peak potentials to more negative values with the increase in scan rate indicated the irreversibility of the reduction processes. In strongly acidic conditions ( $\mathrm{pH} 2.0$ ), the current of peak $1_{\mathrm{c}}$ increased linearly with the square root of $v$, indicating diffusion-limited reduction of analyte. The peak current in amperes for a diffusion-controlled irreversible cathodic process is given by equation [22]

$$
I_{p c}=-2.99 \times 10^{5} n\left(\alpha_{c} n\right)^{1 / 2} A C_{o}^{*} D_{o}^{1 / 2} v^{1 / 2}
$$

where $I_{p c}$ is the cathodic peak current in amperes, $n$ the number of electrons transferred during the reduction, $A$ the geometric area of the electrode in $\mathrm{cm}^{2}, \alpha_{c}$ the cathodic charge transfer coefficient, $D_{o}$ the diffusion coefficient in $\mathrm{cm}^{2} \cdot \mathrm{s}^{-1}, n$ the number of electrons involved in the electrochemical process, $C_{o}{ }^{*}$ the bulk concentration of the oxidant in mol cm${ }^{-3}$ and $v$ the scan rate in $\mathrm{V} \cdot \mathrm{s}^{-1}$.

The difference between peak potential $E_{p c}$ and the potential at half peak height $E_{p c / 2}$ of $\sim 50 \mathrm{mV}$ implied an irreversible 1e reduction. The $\alpha_{c} n$ with a value of 0.95 was calculated from the relation [23]

$$
\left|E_{p c}-E_{p c / 2}\right|=47.7 /\left(\alpha_{c} n\right)
$$

The diffusion coefficient of DDAB with a value of 5.71 $\times 10^{-4} \mathrm{~cm}^{2} \mathrm{~s}^{-1}$ was evaluated from the measured slope $\left(-2.5 \times 10^{-3} \mathrm{~A} /\left(\mathrm{V} \cdot \mathrm{s}^{-1}\right)^{1 / 2}\right)$ of $I_{p c} \mathrm{Vs} v^{1 / 2}$. The $D\left(1.15 \times 10^{-7}\right.$ $\mathrm{cm}^{2} \cdot \mathrm{s}^{-1}$ ) of DDAB was also determined at $\mathrm{pH}$ 7.0. The more current carrying ability as evidenced from high peak current and concomitant $D$ value in strongly acidic medium can be attributed to the greater charge density of cationic DDAB due to non-availability of hydroxide ions. The slightly smaller diffusion coefficient of DAAB at $\mathrm{pH}$ 7.0 than the $D\left(3.70 \times 10^{-7} \mathrm{~cm}^{2} \cdot \mathrm{s}^{-1}\right)$ of a closely related surfactant, cetyltrimethylammonium bromide under similar conditions [24] may be due to its comparatively larger molecular mass, thus confirming the idea that heavy molecule diffuses slowly to the electrode surface.

\subsection{Differential Pulse Voltammetry}

The $\mathrm{pH}$ dependence of DDAB reduction was also investtigated by DPV in acidic, basic and neutral media. Figure 2 shows typical DP voltammograms of $1.0 \mathrm{mM}$ DDAB. Like CV, DDAB showed two reduction peaks in neutral medium but unlike $\mathrm{CV}$, peak $1_{\mathrm{c}}$ did not split into two sub peaks at $\mathrm{pH}$ 2.0. The reason could be the low scan rate $\left(10 \mathrm{mV} \cdot \mathrm{s}^{-1}\right)$ at which the DPV was recorded. Thus the $2^{\text {nd }}$ component of peak $1_{c}$ corresponds to the formation of an electroactive reduction product of DDAB $\left(\mathrm{P}_{\mathrm{DDAB}}\right)$ that can only be observed at higher scan rates. Hence, it is necessary to scan the potential faster than the rate of the homogenous reaction (hydrolysis) that $\mathrm{P}_{\mathrm{DDAB}}$ undergoes in order to observe its redox signals. The absence of peak $2_{\mathrm{c}}$ in the DPV of DDAB at $\mathrm{pH} 2.0$ and its presence in neutral buffer support the results obtained from CV. As the broad peak in DPV was due to two overlapping sub peaks (as described above) so the half peak width $\left(\mathrm{W}_{1 / 2}\right)$ was divided by 2 . A value of $91 \mathrm{mV}$ obtained in this way indicated the transfer of one electron [25].

With the increase in $\mathrm{pH}$, the potential of peak $1_{c}$ was displaced to more negative values (Figure 3). $E_{p c}$ varied linearly (see Inset) with increase in $\mathrm{pH}\left(E_{p c}=0.8443\right.$ $0.0636 \mathrm{pH}$ ). The slope of $63.6 \mathrm{mV}$ per $\mathrm{pH}$ unit close to

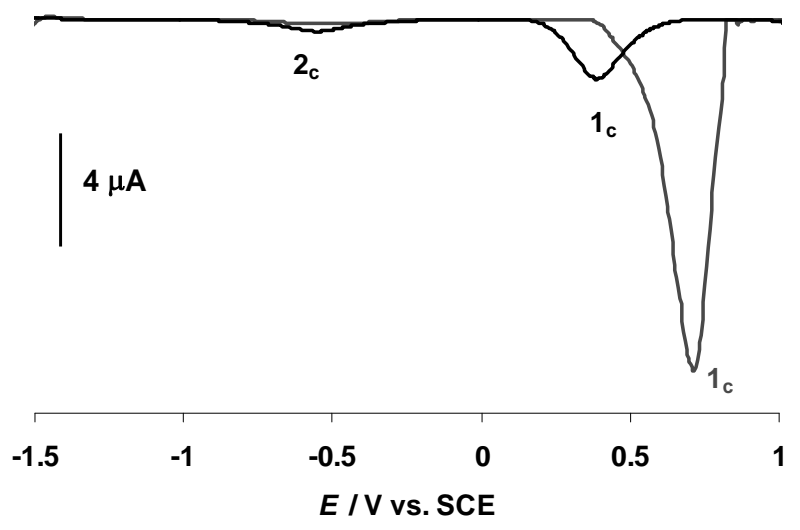

Figure 2. Base line corrected DPVs of $1.0 \mathrm{mM}$ DDAB in pH $2(-)$ and $7(-)$ at a scan rate of $10 \mathrm{mV} \cdot \mathrm{s}^{-1}$. 

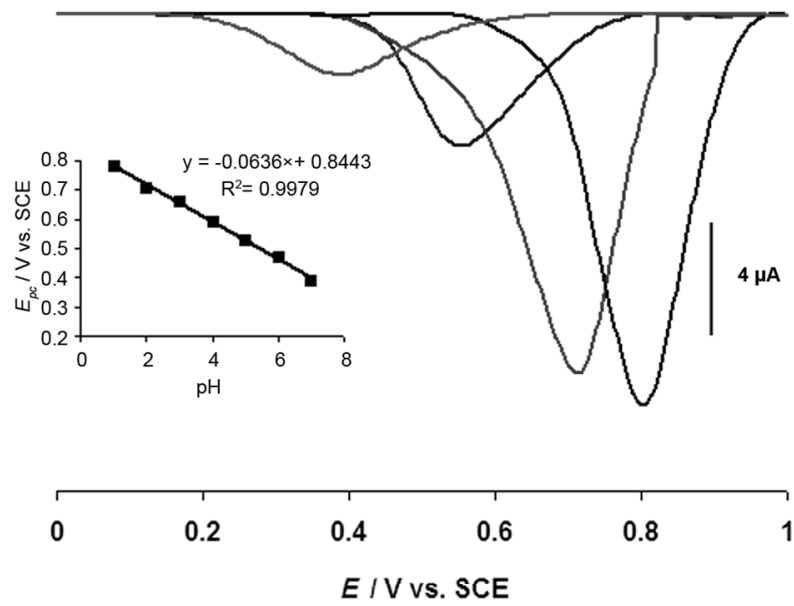

Figure 3. Base line corrected DPVs of $1.0 \mathrm{mM}$ DDAB in pH $1.0(-), 2.0(-), 5.0(-)$ and $7.0(-)$ at $\mathrm{v}=10 \mathrm{mV} \cdot \mathrm{s}^{-1}$. Inset shows $E_{p c}$ as a function of $\mathrm{pH}$.

the theoretical value of 59.5, suggested the involvement of the same number of electrons and protons in the electrochemical reduction of the analyte. Hence, the reduction of DDAB followed $1 \mathrm{e}^{-}, 1 \mathrm{H}^{+}$process in a $\mathrm{pH}$ dependent manner.

In strongly alkaline media the analyte registered only a single anodic peak corresponding to oxidation at $E_{p a}=$ $1.21 \mathrm{~V}$. The DPV under these conditions showed similar features to $\mathrm{CV}$.

\subsection{Square Wave Voltammetry}

SW voltammetry is preferred over other electroanalytical techniques as it is associated with the added advantage of recording forward, backward and net current in only one scan which manifests the reversibility or irreversibility of the electron transfer reaction. Since the current is sampled in both positive and negative-going pulses, peaks corresponding to oxidation and reduction of the electroactive species at the electrode surface can be obtained in the same experiment. Like CV and DPV, both the reduction peaks of $1.0 \mathrm{mM}$ DDAB in $\mathrm{pH} 7.0$ were observed in the forward scan of SW voltammogram at $E_{p c}{ }^{1}=0.51 \mathrm{~V}$ and $E_{p c}{ }^{2}=-0.59 \mathrm{~V}$ (Figure 4(a)). But a dramatically different situation from CV was encountered in the backward scan which showed the reversibility of both peaks. Moreover, the reversibility of peak $1_{c}$ and $2_{c}$ was also evidenced by the equality of the components of total current. Due to the comparatively higher sensitivity of SWV, the reversibility of oxidation peak obtained in alkaline media (Figure 4(b)) was also proved in the same manner and during the same experiment.

Figure 4(c) shows the SW voltammetric behavior of $1.0 \mathrm{mM}$ DDAB at $\mathrm{pH}$ 2.0. Like CV a couple of cathodic

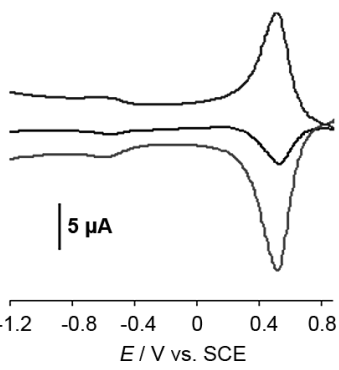

(a)



(b)

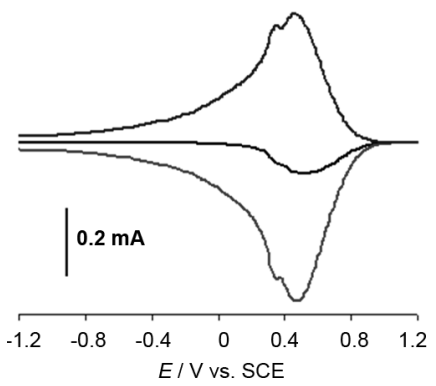

(c)

Figure 4. SWV of $1.0 \mathrm{mM}$ DDAB in $\mathrm{pH}$ (a) 7.0, (b) 13.0 and (c) 2.0 at $v=100 \mathrm{mV} \cdot \mathrm{s}^{-1} \cdot 1^{\text {st }}$ scan in solution showing total current (-), forward current (-) and backward current (一).

peaks corresponding to two close charge transfer reactions were observed in the forward scan. But in contrast to $\mathrm{CV}$, the backward scan indicated the reversibility of both the charge transfer processes. Unlike the SWV at $\mathrm{pH} 7.0$, peak $2_{\mathrm{c}}$ of DDAB was not observed at $\mathrm{pH} 2.0$. The behavior points to the fact that the redox reactions of DA$\mathrm{AB}$ follow different mechanistic pathways in acidic and neutral media.

\subsection{Redox Mechanism}

The results obtained from CV, SWV and DPV enabled to propose the redox mechanism of DAAB (Scheme 2). The appearance of cathodic peak $1_{\mathrm{c}}$ and $2_{\mathrm{c}}$ indicated the reduction of DDAB at the GCE. The splitting of peak $1_{c}$ into two sub peaks at high scan rate revealed the overall reduction of DDAB to occur in three steps. In media buffered at $\mathrm{pH}<7.0$ the components of $1_{\mathrm{c}}$ are attributable to the electrochemical reduction of DDAB (1) to quaternary dodecyldimethylammonium ion (2) and quaternary dimethylammonium ion (3) by a mechanism involving two $1 \mathrm{e}^{-}, 1 \mathrm{H}^{+}$processes. The presence of corresponding oxidation peaks in the reverse scan (Figure 4(c)) suggested the reversibility of DDAB redox processes. Under neutral conditions, the components of peak $1_{c}$ merged into a broad peak that can be related to the formation of reduction product (3) by a mechanism involving $2 \mathrm{e}^{-}, 2 \mathrm{H}^{+}$ transfer. The appearance of $2^{\text {nd }}$ cathodic peak $2_{\mathrm{c}}$ at $\mathrm{pH}=$ 


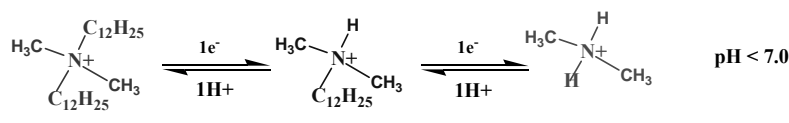

(1)

(2)

(3)

$\underset{\mathrm{C}_{12} \mathrm{H}_{25}}{\mathrm{~N}_{\mathrm{H}+2}^{\mathrm{C}_{12} \mathrm{H}_{25}}} \stackrel{2 \mathrm{e}^{-}}{=}$

(1)

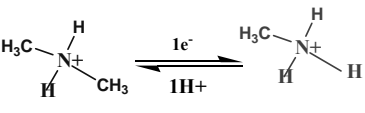

(3)
$\mathrm{pH}=\mathbf{7 . 0}$

(4)



(1)

(5)
Scheme 2. Proposed mechanism for the electrochemical reduction of DDAB.

7.0 pointed to the formation of quaternary methylammonium ion (4). The appearance of anodic peak at $\mathrm{pH} 13.0$ can presumably be due to the oxidation of DAAB to product (5). The mechanism suggested here is supported by the work of Nishiyama et al., [26] on the microbial dealkylation of alkyl trimethylammonium compounds. The presence of dealkylated intermediates of alkyltrimethylammonium salts (triethylamine, dimethylamine and methyllamine) in activated sludge obtained from municipal sewage treatment plant [27] further supported our suggested mechanism. The increase in number of non-methyl alkyl groups in QACs cause difficulty in biodegradability which in turn results in toxicity [27]. Hence, the results of our experiments reveal that QACs can be detoxified to biodegradable products by electrochemical methods.

\subsection{DNA Binding Study}

The effect of increasing concentration of DNA on the cyclic voltammetric response of $1.0 \mathrm{mM}$ DDAB has been shown in Figure 5. Unlike the general trend, the peak current of DDAB increased in the presence of DNA. This anomalous behavior may be due to the dissociation of DDAB micelles by DNA and concomitant increase in number of monomers. The breakdown of micellar aggregates can be due to electrostatic interaction of anionic oxygen with ammonium moiety and the affinity of hydrophobic interior of DNA for the lipophilic hydrocarbon section of DAAB. The increase in peak current further points to the fact that the number of monomers produced by the breakdown of micelles is greater in the bulk than those attached with DNA. The peak potential shift to more negative and then to positive values is attributed to
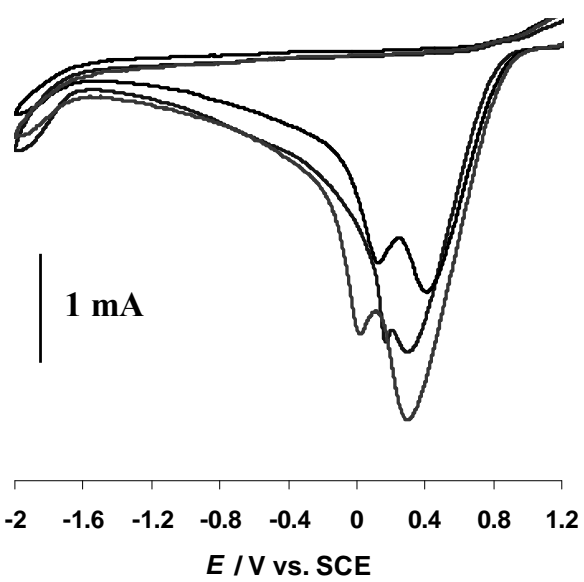

Figure 5. $1^{\text {st }}$ scan CVs of 1.0 mM DDAB (obtained in pH 2.0) in the absence of DNA (-) and presence of $20(-)$ and 40 M DNA (一).

mixed binding mode. A part of the hydrocarbon tail of DDAB is suggested to intercalate and the rest may occupy the grooves. The cationic ammonium moiety may interact electrostatically with anionic phosphate backbone of DNA. The interaction is expected to effect the DNA of cancerous cells in such a way that the cell can not replicate further.

The peak current of DAAB diminished with further incremental addition of DNA. The rationale behind the diminution in peak current may be the decrease in number of free monomers due to the formation of macromolecular DAAB-DNA complex with lower current carrying ability.

The decay in peak current $\left(I_{p}\right)$ of DAAB by the incremental addition of DNA was exploited for the quantification of binding constant according to the following equation [28]

$$
\log (1 /[\mathrm{DNA}])=\log K+\log \left(I /\left(I_{o}-I\right)\right)
$$

where $K$ is the binding constant, $I_{o}$ and $I$ are the peak currents of the drug in the absence and presence of DNA. The $K$ with a value of $3.41 \times 10^{4} \mathrm{M}^{-1}$ was obtained from the intercept of $\log (1 /[\mathrm{DNA}])$ versus $\log \left(I /\left(I_{0}-I\right)\right)$ plot. The value is comparable with the reported $K\left(3.60 \times 10^{4}\right.$ $\mathrm{M}^{-1}$ ) of 1,8-dihydroxyanthraquinone interacting with DNA by mixed binding mode [29].

For the determination of binding site size the following equation was used [30]

$$
C_{b} / C_{f}=K\{[\mathrm{DNA}] / 2 s\}
$$

where $s$ is the binding site size in terms of base pairs, $C_{f}$ the concentration of the free species, $C_{b}$ the concentration of DNA-bound species and $K$ the binding constant. The values of $C_{b} / C_{f}$ were determined from the experimental peak currents by the following equation [30]. 


$$
C_{b} / C_{f}=\left(I_{o}-I\right) / I
$$

By inserting $K=3.41 \times 10^{4} \mathrm{M}^{-1}$ in Equation (4), the binding site size with a value of $0.51 \mathrm{bp}$ was obtained from the slope of $C_{b} / C_{f}$ versus [DNA] plot. The value of $s$ implies that the binding parts of two molecules of $\mathrm{DAAB}$ can occupy one base pair.

The $D$ of DAAB with a value of $3.22 \times 10^{-5} \mathrm{~cm}^{2} \cdot \mathrm{s}^{-1}$ was obtained in the presence of $100 \mathrm{M}$ DNA at $\mathrm{pH} 2.0$. The lower value of $D$ in the presence of DNA corresponds to the formation of slow moving heavy DAABDNA adduct.

Using the values of $D$ measured from $\mathrm{CV}$ data, the electrophoretic mobility $(u)$ of DAAB was determined as $2.22 \times 10^{-6}$ and $4.48 \times 10^{-10} \mathrm{~m}^{2} \cdot \mathrm{s}^{-1} \cdot \mathrm{V}^{-1}$ in media buffered at $\mathrm{pH} 2.0$ and 7.0 by the equation [31]

$$
u=z e D / K_{B} T
$$

The lower mobility of DAAB in neutral medium can be related to its interaction with the available hydroxyl groups. In the presence of DNA the $u$ of DAAB lowered to $1.25 \times 10^{-7} \mathrm{~m}^{2} \cdot \mathrm{s}^{-1} \cdot \mathrm{V}^{-1}$ at $\mathrm{pH} 2.0$. The decrease in $u$ may be due to the formation of bulky DAAB-DNA adduct.

The radius $\left(9.55 \times 10^{-10} \mathrm{~m}\right)$ of the solvated DAAB was calculated by Stokes-Einstein equation

$$
r=K_{\mathrm{B}} T / 6 \pi \eta D
$$

where $\eta$ is the viscosity of the solvent, $D$ the diffusion coefficient, $T$ temperature and $K_{B}$ Boltzmann's constant.

The radius $\left(5.36 \times 10^{-10} \mathrm{~m}\right)$ of the compound in the solid state was obtained from density measurements by using the following relation

$$
V=(4 / 3) \pi r^{3}
$$

It can be seen that the radius of DDAB in the solvated form is greater than that in the solid form, as expected.

The mean hydrodynamic radius $(1.1 \mathrm{~nm})$ of DAAB was determined by laser light scattering technique. The value supports the result obtained from viscosity and $\mathrm{CV}$ measurements.

The critical micelle concentration (CMC) of DAAB was determined (See Figure 6) by conductivity method. The value of $0.48 \mathrm{mM}$ ensured the micellar nature of DAAB solution used for DNA binding studies. The $\mathrm{CMC}$ value determined here is more than $0.05 \mathrm{mM}$ and less than $2.5 \mathrm{mM}$ as reported by Atkin et al. [32] and Antonella et al. [33]. The differences may be due to several factors like variation in $\mathrm{pH}$, temperature, counter ion and ionic strength of the solution.

\section{Conclusions}

The present study has shown that DDAB can be reduced and oxidized at a glassy carbon electrode. The reduction

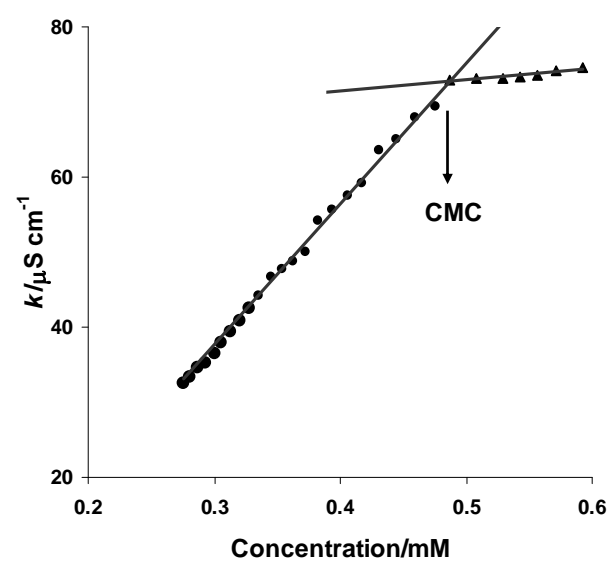

Figure 6. Specific conductance as a function of concentration.

of DDAB was found to depend strongly on the $\mathrm{pH}$ of the medium. In acidic conditions the mechanism involved the transfer of two electrons and two protons. However, in neutral medium the overall reduction of DAAB occurred by a $3 \mathrm{e}^{-}, 3 \mathrm{H}^{+}$process. Oxidation was evidenced only in strongly alkaline conditions. All the peaks were found reversible by square wave voltammetry. The diffusion coefficient in $\mathrm{pH} 2.0$ was found greater than in $\mathrm{pH}$ 7.0. The electrochemical characterization of DDAB has the potential of providing valuable insights about the unexplored pathways by which QACs are detoxified. The binding constant, binding site size, diffusion coefficient and electrophoretic mobility were determined from cyclic voltammetric and viscosity data. Moreover, the radii of the solvated and solid $\mathrm{DAAB}$ were evaluated from electrochemical and laser light scattering techniques. The hydrodynamic radius of the solvated DAAB was found greater than the solid form as expected. The investigation of the electrochemical behaviour of DDAB and its interaction with DNA is expected to provide useful insights about the mechanism by which miceller solution of toxic anticancer drugs exert their biochemical action.

\section{Acknowledgements}

The authors gratefully acknowledge Quaid-i-Azam University and Higher Education Commission Islamabad, Pakistan, for providing financial assistance.

\section{References}

[1] Y. Kuboyama, K. Suzuki and T. Hara, "Nasal Lesions Induced by Intranasal Administration of Benzalkonium Chloride in Rats," Journal of Toxicological Sciences, Vol. 22, No. 2, 1997, pp. 153-160. doi:10.2131/jts.22.2 153

[2] B. Nicola, E. Nicolas, R. Junice and V. Glyn, "Paediatric 
Toxicology Handbook of Poisoning in Children," Macmillan Reference Ltd., London, 1997.

[3] R. Beasley, D. Fishwick, J. F. Miles and L. Hendeles, "Preservatives in Nebulizer Solutions: Risks without Benefit," Pharmacotherapy, Vol. 18, 1998, pp. 130-139.

[4] P. S. Boeris, A. S. Liffourrena, M. A. Salvano and G. I. Lucchesi, "Physiological Role of Phosphatidylcholine in the Pseudomonas putida A ATCC 12633 Response to Tetradecyltrimethylammonium Bromide and Aluminium," Letters in Applied Microbiology, Vol. 49, No. 4, 2009, pp. 491-496. doi:10.1111/j.1472-765X.2009.02699.x

[5] R. P. Singh, N. Gupta, S. Singh, A. Singh, R. Suman and K. Annie, "Toxicity of Ionic and Non Ionic Surfactants to Six Microbes Found in Agra, India," Bulletin of Environmental Contamination and Toxicology, Vol. 69, No. 2, 2002, pp. 265-270. doi:10.1007/s00128-002-0056-Z

[6] F. Placucci, A. Benini and A. Tosti, "Occupational Allergic Contact Dermatitis from Disinfectant Wipes Used in Dentistry," Contact Dermatitis, Vol. 35, No. 5, 1996, p. 306. doi:10.1111/j.1600-0536.1996.tb02397.x

[7] D. Chataigner, R. Garnier, S. Sans and M. L. Efthymiou, "Intoxication Aigue Accidentelle Par un Désinfectant Hospitalier. 45 cas dont 13 d'évolution Mortelle," La Presse Médicale, Vol. 20, 1991, pp. 741-743.

[8] M. Van Berkel and F. A. de Wolff, "Survival after Benzalkonium Chloride Poisoning," Human Toxicology, Vol. 7, 1988, pp. 191-193. doi:10.1177/096032718800700216

[9] R. Ren, D. Liu, K. Li, J. Sun and C. Zhang, "Adsorption of Quaternary Ammonium Compounds onto Activated Sludge," Journal of Water Resource and Protection, Vol. 3, No. 2, 2011, pp. 105-113. doi:10.4236/jwarp.2011.32012

[10] M. T. Garcia, E. Campos, J. Sanchez-Leal and I. Risoba, "Anaerobic Degradation and Toxicity of Commercial Cationic Surfactants in Anaerobic Screening Tests," Chemosphere, Vol. 41, No. 5, 2000, pp. 705-710. doi:10.1016/S0045-6535(99)00455-5

[11] H. T. Chifotides and K. R. Dunbar, "Interactions of Metal-Metal-Bonded Antitumor Active Complexes with DNA Fragments and DNA," Accounts of Chemical Research, Vol. 38, No. 2, 2005, pp. 146-156. doi:10.1021/ar0302078

[12] D. D. Li, J. L. Tian, W. Gu, X. Liu, H. H. Zeng and S. P. Yan, "DNA Binding, Oxidative DNA Cleavage, Cytotoxicity, and Apoptosis-Inducing Activity of Copper(II) Complexes with 1,4-Tpbd( $N, N, N^{\prime}, N^{\prime}$-tetrakis(2-yridylmethyl)benzene-1,4-diamine) Ligand," Journal of Inorganic Biochemistry, Vol. 105, No. 6, 2011, pp. 894-901. doi:10.1016/i.jinorgbio.2011.03.012

[13] M. Egli, L. D. Williams, C. A. Frederick and A. Rich, "DNA-Nogalamycin Interactions," Biochemistry, Vol. 30, No. 5, 1991, pp. 1364-1372.

[14] A. Fontana, P. D. Maria, G. Siani and B. H. Robinson, "Kinetics of Breakdown of Vesicles from Didodecyldimethylammonium Bromide Induced by Single Chain Surfactants and by Osmotic Stress in Aqueous Solution,"
Colloids and Surfaces B: Biointerfaces, Vol. 32, No. 4, 2003, pp. 365-374.

doi:10.1016/j.colsurfb.2003.08.003

[15] M. Gradzielski, "Recent Developments in the Characterization of Microemulsions," Current Opinion in Colloid \& Interface Science, Vol. 13, No. 4, 2008, pp. 263269. doi:10.1016/j.cocis.2007.10.006

[16] K. Kusumoto and T. Ishikawa, "Didodecyldimethylammonium Bromide (DDAB) Induces Caspase-Mediated Apoptosis in Human Leukemia HL-60 Cells," Journal of Controlled Release, Vol. 147, No. 2, 2010, pp. 246-252. doi:10.1016/j.jconrel.2010.07.114

[17] T. Neumann, S. Gajria, N. Bouxsein, L. Jaeger and M. Tirrell, "Structural Responses of DNA-DDAB Films to Varying Hydration and Temperature," Journal of the American Chemical Society, Vol. 132, No. 20, 2010, pp. 7025-7037. doi:10.1021/ja909514j

[18] N. Subramanian, S. K. Ghosal, A. Acharya and S. P. Moulik, "Formulation and Physicochemical Characterization of Microemulsion System Using Isopropyl Myristate, Medium-Chain Glyceride, Polysorbate 80 and Water," Chemical \& Pharmaceutical Bulletin, Vol. 53, No. 12, 2005, pp. 1530-1535. doi:10.1248/cpb.53.1530

[19] A. Shah, A. M. Khan, R. Qureshi, F. L. Ansari, M. F. Nazar and S. S. Shah, "Redox Behavior of Anticancer Chalcone on a Glassy Carbon Electrode and Evaluation of Its Interaction Parameters with DNA," International Journal of Molecular Sciences, Vol. 9, No. 8, 2008, pp. 1424-1434. doi:10.3390/ijms9081424

[20] M.-J. Han, Z.-M. Duan, et al., "Molecular Light Switches for Calf Thymus DNA Based on Three Ru(II) Bipyridyl Complexes with Variations of Heteroatoms," The Journal of Physical Chemistry C, Vol. 111, No. 44, 2007, pp. 16577-16585. doi:10.1021/jp075194k

[21] D. L. Guo, Y. Xin, P. C. Zeng, L. S. Guo and Q. Y. Ru, "Interaction of Metal Complexes of Bis(salicylidene)ethylenediamine with DNA," Analytical Sciences, Vol. 16, No. 12, 2000, pp. 1255-1260.

doi:10.2116/analsci.16.1255

[22] C. M. A. Brett and A. M. O. Brett, "Electrochemistry. Principles, Methods and Applications," Oxford University Press, Oxford, 1993.

[23] V. C. Diculescu, T. A. Enache, P. J. Oliveira and A. M. O. Brett, "Electrochemical Oxidation of Berberine and of Its Oxidation Products at a Glassy Carbon Electrode," Electroanalysis, Vol. 21, No. 9, 2009, pp. 1027-1034. doi:10.1002/elan.200804516

[24] B. M. Asit and U. N. Balachandran, "Cyclic Voltammetric Technique for the Determination of the Critical Micelle Concentration of Surfactants, Self-Diffusion Coefficient of Micelles, and Partition Coefficient of an Electrochemical Probe," Journal of Physical Chemistry, Vol. 95 No. 22, 1991, pp. 9008-9013. doi:10.1021/j100175a106

[25] A. Shah, V. C. Diculescu, R. Qureshi and A. M. O. Brett, "Electrochemical Behavior of Dimethyl-2-oxoglutarate on Glassy Carbon Electrode," Bioelectrochemistry, Vol. 77, No. 2, 2010, pp. 145-150. 
doi:10.1016/i.bioelechem.2009.07.012

[26] N. Nishiyama, Y. Toshima and Y. Ikeda, "Biodegradation of Alkyltrimethylammonium Salts in Activated Sludge," Chemosphere, Vol. 30, 2009, pp. 593-603. doi:10.1016/0045-6535(94)00406-K

[27] D. Y. Guang, "Fate, Behaviour and Effects of Surfactants and Their Degradation Products in the Environment," Environmental International, Vol. 32, No. 3, 2006, pp. 417-431. doi:10.1016/j.envint.2005.07.004

[28] Q. Feng, N. Q. Li and Y. Y. Jiang, "Electrochemical Studies of Porphyrin Interacting with DNA and Determination of DNA," Analytica Chimica Acta, Vol. 344, No. 1-2, 1997, pp. 97-104. doi:10.1016/S0003-2670(97)00008-1

[29] M. B. Gholivand, S. Kashanian, H. Peyman and H. Roshanfekr, "DNA-Binding Study of Anthraquinone Derivatives Using Chemometrics Methods," European Journal of Medicinal Chemistry, Vol. 46, No. 7, 2011, pp. 2630-2638. doi:10.1016/j.ejmech.2011.03.034
[30] M. Aslanoglu and N. Oge, "Voltammetric, UV Absorption and Viscometric Studies of the Interaction of Norepinephrine with DNA," Turkish Journal of Chemistry, Vol. 29, 2005, pp. 477-485.

[31] D. F. Evans and H. Wennerstrom, "The Colloidal Domain: Where Physics, Chemistry, Biology, and Technology Meet," VCH Publishers Inc., New York, 1994.

[32] R. Atkin, V. S. J. Craig, E. J. Wanless and S. Biggs, "Mechanism of Cationic Surfactant Adsorption at the Solid-Aqueous Interface," Advances in Colloid and Interface Science, Vol. 103, No. 3, 2003, pp. 219-304. doi:10.1016/S0001-8686(03)00002-2

[33] F. Antonella, D. M. Paolo, S. Gabriella and H. R. Brian, "Kinetics of Breakdown of Vesicles from Didodecylammonium Bromide Induced by Single Chain Surfactants and by Osmotic Stress in Aqueous Solution," Colloids and Surfaces B: Biointerfaces, Vol. 32, No. 4, 2003, pp. 365-374. doi:10.1016/j.colsurfb.2003.08.003 